Board of Governors of the Federal Reserve System

International Finance Discussion Papers

Number 720

February 2002

IDENTIFYING VARS BASED ON HIGH FREQUENCY FUTURES DATA

Jon Faust, Eric Swanson and Jonathan H. Wright

NOTE: International Finance Discussion Papers are preliminary materials circulated to stimulate discussion and critical comment. References in publications to International Finance Discussion Papers (other than an acknowledgment that the writer has had access to unpublished material) should be cleared with the author or authors. Recent IFDPs are available on the Web at www.federalreserve.gov/pubs/ifdp/. 


\title{
IDENTIFYING VARS BASED ON HIGH FREQUENCY FUTURES DATA
}

\author{
Jon Faust, Eric Swanson and Jonathan H. Wright*
}

\begin{abstract}
Using the prices of federal funds futures contracts, we measure the impact of the surprise component of Federal Reserve policy decisions on the expected future trajectory of interest rates. We show how this information can be used to identify the effects of a monetary policy shock in a standard monetary policy VAR. This constitutes an alternative approach to identification that is quite different, and, we would argue, more plausible, than the conventional short-run restrictions. We find that the usual recursive identification of the model is rejected, but we nevertheless agree with the literature's conclusion that only a small fraction of the variance of output can be attributed to monetary policy shocks.
\end{abstract}

${ }^{*}$ Board of Governors of the Federal Reserve System. We are grateful to Graham Elliott, Jim Hamilton, Andy Levin, Jennifer Roush and Carl Walsh for helpful comments. We are grateful to Shing-Yi Wang for superlative research assistance and to Charles Evans for providing us with his commodity price data. The views in this paper are solely the responsibility of the authors and should not be interpreted as reflecting the views of the Board of Governors of the Federal Reserve System or of any person associated with the Federal Reserve System. 


\section{Introduction}

Since the seminal paper of Sims (1980), much attention has been devoted to studying the effects of monetary policy on macroeconomic variables within the framework of a vector autoregression (VAR). This approach relies on making identifying assumptions relating structural shocks to the reduced form errors of the VAR. While many identification approaches have been proposed for identifying VARs, most often short-run restrictions are used. These specify that some structural shock has no contemporaneous effect on one or more variables. For example, it might be assumed that monetary policy has no contemporaneous effect on output and prices. Such identifying assumptions are used by Sims (1980) and in most papers in the VAR literature, including Christiano, Eichenbaum and Evans $(1996,1999)$. Other approaches to the identification of a VAR include the use of long-run restrictions that come from neutrality or super neutrality arguments about the effects of monetary policy on real variables. For example, King and Watson (1997) make the assumption that monetary policy shocks have no long-run effect on output, and show that this long-run neutrality condition allows the identification of a simple VAR.

Extant studies of the effects of monetary policy in a VAR differ greatly in their identifying assumptions and in the choice of the variables to include in the system. Nonetheless, most of these studies tend to agree on the qualitative effect of monetary policy shocks on macroeconomic variables. For example, most work of this type finds that monetary policy shocks account for a small portion of the forecast error variance of output. This important 
conclusion is tempered by a concern about the strength of the identifying assumptions on which it rests.

While the identifying assumptions are plausible, none is uncontroversial: we have many reasons taken from both theory and empirical evidence to believe that they will not hold exactly in the data (see, for example, Faust (1998), Leeper, Sims and Zha (1996) and Uhlig (1999)). This would not be troubling if the resulting conclusions appeared to be robust to minor deviations from the assumptions. Unfortunately, this robustness is difficult to check. Various authors have proposed approaches to testing robustness, and the conclusions are mixed at best. For example, Faust (1998) finds that allowing a small contemporaneous effect on output allows one to identify monetary policy shocks that account for a large portion of the forecast error variance of output.

While the conclusions from this literature are highly plausible to many of us, since the conclusions are sensitive to easily questioned assumptions, it is not clear that literature has (or should have) changed the minds of those who are inclined to disagree.

In this paper, we maintain the standard assumption that there exists some way to identify the impulse response to a policy shock in these models. We hope to bolster the credibility of conclusions about policy shocks by bringing to bear additional information from the federal funds rate futures market in the identification step of the exercise.

There are two key steps in our procedure. First, we measure the impulse response of the federal funds rate to the policy shock directly using federal funds rate futures data only. 
Second, we identify a standard VAR by imposing that the impulse response of the funds rate to the policy shock in the VAR match the one measured from futures data. While these two steps are conceptually straightforward, carefully implementing in practice requires dealing with several complications. In the first step, measuring the response of the funds rate to policy shocks in the futures data requires taking account of several peculiar aspects of that market. The validity of our approach rests on some substantive assumptions, which we test. In the second step, we find that the information from the futures market only partially identifies the system, so we must use inference approaches that are reliable under weak identification.

Our approach is closely related to independent work of Cochrane and Piazzesi (2002). They also achieve identification from the assumption that the unexpected change in the target fed funds rate (measured from the futures market) represents exogenous variation in monetary policy, though they do not use the futures market to measure the response of expected future interest rates to the unexpected change in the target fed funds rate.

Our principal conclusions are that the standard recursive identification is rejected: it is inconsistent with the evidence from the fed funds futures market. One of the main consensus results from the identified VAR literature however gains renewed support. We find that the share of the forecast error variance of output due to policy shocks is small, with our confidence interval being similar to that found under the recursive identification. This result is striking because we use much weaker, and we argue more plausible, restrictions 
than in the existing literature.

The plan for the remainder of this paper is as follows. We discuss the identification problem in section 2 and estimate the impulse response of the funds rate from futures data in section 3. Our primary results are in section 4 and we take up robustness in section 5 . Conclusions are in section 6.

\section{Identification}

\subsection{The simplest case}

Consider the reduced form VAR,

$$
A(L) Y_{t}=u_{t}
$$

where $Y_{t}$ is $G \times 1, A(L)=\sum_{j=0}^{\infty} A_{j} L^{j}$ and $A_{0}=I$. Following the literature we assume that $A(L)$ is invertible so that the system can be written as,

$$
Y_{t}=B(L) u_{t}
$$

where $B(L)=A(L)^{-1}$.

The identified VAR literature makes the assumption that the $G$ reduced form errors $u_{t}$ are related to structural errors by the relation: $u_{t}=S \varepsilon_{t}$, where $S$ is full rank. One of the structural shocks is assumed to be the monetary policy shock of interest. We can order 
things such that this is the first structural shock. The VAR can be written in terms of the structural shocks as,

$$
Y_{t}=B(L) S \varepsilon_{t}
$$

Call the first column of $S, \alpha$; this is the column corresponding to the policy shock. The impulse response of all variables in the VAR to the policy shock is,

$$
B(L) \alpha=\sum_{j=0}^{\infty} B_{j} \alpha L^{j}
$$

This is a $G \times 1$ vector of lag polynomials and the coefficients of the $g^{\text {th }}$ element trace out the response of the $g^{\text {th }}$ variable to the policy shock.

The $B$ s are given by the reduced form estimates and so identifying the impulse response requires picking the $G$ elements of $\alpha$. One restriction is a normalization, choosing the sign and units of the policy shock. In most work, one normalizes the standard deviation of the shock to be 1 . In our work, the VAR includes the federal funds rate and we normalize the shock to have a contemporaneous +25 basis point effect on the federal funds rate. ${ }^{1}$

We complete the identification by requiring that the impulse response of the funds

\footnotetext{
${ }^{1}$ The choice of normalizing the impact effect or the standard deviation of the shock is innocuous in the point estimates. Suppose a one standard deviation shock has a +25 basis point effect in the point estimates. A 95 percent confidence interval for the effects of a one standard deviation shock need not be a 95 percent confidence interval for a 25 basis point shock. This is because the impact effect of a one standard deviation shock is stochastic. Our normalization is chosen for two reasons. It is technically convenient, and it leads to confidence intervals for something we want to learn: the effects of a given size. We are less interested in the effects of a 1 standard deviation shock, where the value of the standard deviation is not stipulated.
} 
rate to the policy shock match the response measured in the futures market data. For now simply take it as given that we know that the response of the funds rate to a policy shock at $t$ is $r_{h}, h=0,1, \ldots, G-1$ at time $t+h$. This measure has been normalized so that the contemporaneous effect is +25 basis points: $r_{0}=0.25$.

To see algebraically how the $r_{h}$ S allow us to pick out the element of $\alpha$, note that the response at horizon $h$ of the funds rate to the shock is

$$
B_{h, f f} \alpha,
$$

where $B_{h, f f}$ is the row of $B_{h}$ corresponding to the funds rate. Our identification requires that

$$
B_{h, f f} \alpha=r_{h}, \ldots, \quad h=0,1, \ldots, G-1 .
$$

We can stack these $G$ equations to form

$$
R \alpha=r
$$

where the rows of $R$ are the relevant row vectors $B_{h, f f}$ and the elements of $r$ are the corresponding elements $r_{h}$. If $R$ is of $\operatorname{rank} G$, then there is a unique solution to this equation and $\alpha=R^{-1} r$.

\subsection{Factors complicating inference}


In the above discussion, we treated $R$ and $r$ as known. In practice $R$ will be implied by the reduced form estimates of the VAR and $r$ will be estimated from the futures market data. We must take account of uncertainty in each when doing our inference. More problematically, the identification rests on the rank condition that the rank of $R$ is $G$. When we test the rank of our estimated $R \mathrm{~s}$ below, we cannot reject rank deficiency. Thus our restrictions $R \alpha=r$ leave the system only partially identified. The reason for this is clear: the response of the funds rate at different horizons in the reduced form is very $\operatorname{similar}\left(B_{h, f f} \approx B_{h+1, f f}\right)$, so after imposing the impulse response to the shock at horizon $h$, one gets very little additional identifying power from also imposing the response at $h+1$ or $h+2$.

One might suppose that failure of the rank condition dooms inference. When identifying the slope parameters of simultaneous equations models using linear restrictions, individual parameters are either fully identified or valid confidence intervals for them are unbounded. In the nonlinear case (relevant to objects such as variance shares), a valid confidence interval for a parameter may be bounded even if it is not fully identified. Failure of the rank condition does not doom inference, but we must take proper account of the partial identification. The most striking implication of partial identification is that we must give up on point estimation and only consider confidence intervals. Moreover, these confidence intervals must be constructed in a way that is robust to the failure of the rank condition.

\subsection{Confidence intervals under partial identification}

Suppose we want to learn about some scalar parameter $f$. This could be the share of the 
forecast error variance of output at horizon 48 due to the policy shock or the impulse response of prices to the policy shock at some horizon. Calling all the reduced form parameters of the VAR $\theta, f$ is a function of $\theta$ and $\alpha: f(\theta, \alpha)$. Let $\hat{\theta}$ denote the OLS estimate of $\theta$.

We can form a $95 \%$ confidence set for $\alpha$ by a method that takes account of uncertainty in $R$ and $r$, and that does not rely on assumptions about the rank of $R$. The construction of this confidence set follows the work of Stock and Wright (2000) and is discussed in detail in the appendix. We call this confidence set $A$.

First fix $\theta$ at the reduced form point estimate $\hat{\theta}$. Under full identification, this would be associated with a unique estimate of $f$. In the current case, we can find the range of $f(\hat{\theta}, \alpha)$ consistent with $\alpha$ in our confidence set $A$ :

$$
\left[\inf _{\alpha \varepsilon A} f(\hat{\theta}, \alpha), \sup _{\alpha \varepsilon A} f(\hat{\theta}, \alpha)\right]
$$

Taking account of uncertainty in $\alpha$ and $\theta$ simultaneously requires a slightly more complicated argument. For any fixed $\alpha$, the model is identified, and so we can use a conventional bootstrap to construct a confidence interval for $f(\theta, \alpha){ }^{2}$ Let this confidence interval be $[\underline{\mathrm{c}}(\alpha), \bar{c}(\alpha)]$. Next form the outer envelope of all of these intervals across all $\alpha \mathrm{s}$ in $A$, as $\left[\inf _{\alpha \varepsilon A} \underline{\mathrm{c}}(\alpha), \sup _{\alpha \varepsilon A} \bar{c}(\alpha)\right]$. This confidence interval has asymptotic coverage of at least $90 \%$, from the Bonferroni inequality, because asymptotically (i) the true $\alpha$ is included in $A$ with

\footnotetext{
${ }^{2}$ Each bootstrap replication holds $\alpha$ fixed but calculates a new $\theta$ from the bootstrap sample.
} 
probability $95 \%$, and (ii) the bootstrap confidence interval has $95 \%$ coverage for any fixed $\alpha$. The technique is conservative in that coverage may asymptotically be higher than 90 percent. ${ }^{3}$ The resulting confidence interval may be wide, reflecting in part its construction as a conservative confidence interval using the Bonferonni inequality.

\section{Federal Funds Futures and the impulse response to policy shocks}

This section develops the claim, taken as given in the last section, that the impulse response of the funds rate to policy shocks can be measured directly from the federal funds rate futures market.

The federal funds rate futures contract for month $t+h$ is a bet on the monthly average effective funds rate in month $t+h$, call it $f_{t+h} \cdot{ }^{4}$ These contracts trade during business hours on business days. To allow for daily time indices, we maintain our convention that $t$ is a monthly time index corresponding to data in the VAR, and write $d_{t}$ for day $d$ in month $t$. For simplicity, we sometimes drop the $t$ subscript, but a $d$ time script is always a day in month $t$.

Parties to the contract on day $d_{t}$ agree on a rate $f_{d_{t}}^{h}$ and then exchange $f_{d_{t}}^{h}-f_{t+h}$ in cash at the end of month $t+h$. With no money up front, standard no arbitrage reasoning implies

\footnotetext{
${ }^{3}$ For example, even when the true $\alpha$ is not in $A$, the confidence interval may contain the true $f$.

${ }^{4}$ The New York Fed produces the daily effective rate, and the monthly average is an average for all days in the month. The rate for non-business days is the previous business day's rate.
} 
that $0=E_{t}\left[m_{t+h}\left(f_{t+h}-f_{d}^{h}\right)\right]$, where $m_{t+h}$ is the stochastic pricing kernel. Re-arranging gives,

$$
f_{d}^{h}=E_{t} f_{t+h}+\frac{\operatorname{cov}_{d}\left(f_{t+h}, m_{t+h}\right)}{E_{t}\left[m_{t+h}\right]},
$$

where $\operatorname{cov}_{d}$ is the conditional covariance seen from time $d_{t}$. Thus, the futures rate is equal to the expected future funds rate plus a risk term.

We will focus on the change in the futures rate on the day of announced changes in the Fed's target federal funds rate. On any such day $d_{t}$ we have

$$
f_{d_{t}}^{h}-f_{d_{t}-1}^{h}=\left(E_{d_{t}}-E_{d_{t}-1}\right) f_{t+h}
$$

plus the change in the conditional covariance term over the day.

Our first substantive assumption is that the conditional covariance term can be neglected so that there is no change-in-risk term in (4). We provide arguments and statistical tests to support this assumption in Section 5 .

Under our assumption, the change in the futures market equals the change in the market's expectation. We next assume that this change on FOMC announcement days is due to an exogenous monetary policy shock. It should be uncontroversial that any surprise in the FOMC announcement could rightly be construed, at least in part, as a policy shock. Our requirement is much stronger. There are two primary ways this could fail: the FOMC could be reacting to data hitting the market that day - the FOMC acts on the day of a surprising 
employment report. More problematic is the case in which the FOMC's announcement itself reveals macro data that is private information of the Fed. We provide arguments and evidence supporting our assumption in Section 5 .

With these assumptions, we have,

$$
\Delta f_{d}^{h}=\Delta_{d}^{e} f_{t+h}
$$

where $\Delta$ is the daily change operator and $\Delta_{d_{t}}^{e}$ is the corresponding change in expectations operator: $\Delta_{d_{t}}^{e}=\left(E_{d_{t}}-E_{d_{t}-1}\right)$.

Now return to the VAR. The expected funds rate at $t+h$ conditional on information in the monthly dataset at time $t$ is,

$$
E_{t} f_{t+h}=\sum_{i=0}^{\infty} B_{h+i, f f} S \varepsilon_{t-i}
$$

The change in the expectation from day $d_{t}-1$ to $d_{t}$ during month $t$ can only be due to changes in the expectations of the $u$ s over this day. Of course, all the past $\varepsilon \mathrm{s}\left(\varepsilon_{t-1}\right.$, etc. $)$ are known at the beginning of month $t$, so that the change expectations only be due to a change in the expectation of $\varepsilon_{t}: \Delta_{d_{t}}^{e} \varepsilon_{t}{ }^{5}$ Thus,

$$
\Delta_{d_{t}}^{e} f_{t+h}=B_{h, f f} S \Delta_{d_{t}}^{e} \varepsilon_{t}
$$

\footnotetext{
${ }^{5}$ During month $t$, information about the month $t$ shock accumulates, future shocks remain unknown and past shocks are already known.
} 
We can write the righthand side as the change in the expectation of the policy shock, $\varepsilon_{1 t}$, plus terms involving changes in expectations of the other shocks: ${ }^{6}$

$$
\Delta_{d_{t}}^{e} f_{t+h}=B_{h, f f} \alpha \Delta_{d_{t}}^{e} \varepsilon_{1 t}+\nu_{h t}
$$

Our second assumption is that $\nu_{h t}=0$ : neither other news, nor the policy announcement itself leads the market to reassess its view of the other shocks. Combining (5) and (6) gives,

$$
\Delta f_{d}^{h}=r_{h} \Delta_{d_{t}}^{e} \varepsilon_{1 t}
$$

where $r_{h}=B_{h, f f} \alpha$ is the impulse response of the funds rate to the policy shock at horizon $h$. Since this equation holds for all $h$, we can substitute out the unobserved quantity $\Delta_{d_{t}}^{e} \varepsilon_{1 t}$ with $\Delta f_{0}^{h} / r_{0}$ to get:

$$
\Delta f_{d}^{h}=\frac{r_{h}}{r_{0}} \Delta f_{d}^{0}
$$

This says that for every day of a policy change, the change in the futures market at different horizons should be proportional and the factor of proportionality is the same every day (only the magnitude of the shock changes). We will estimate this factor of proportionality from the data and then use the normalization $r_{0}=+25$ basis points to obtain the estimated $\hat{r}_{h} \mathrm{~s}$ used in our identification.

\footnotetext{
${ }^{6}$ Formally, $\nu_{t}=B_{h, f f} S^{*} \varepsilon_{t}$, where $S^{*}$ is $S$ with the first column replaced by zeros.
} 


\subsection{The Federal Funds Futures data}

We focus on the daily change (close-to-close) in the federal funds futures rates on the day of FOMC meetings and other announced changes in the Fed's target federal funds rate. There exist futures contracts on the current month and for 1 through 5 months in the future. ${ }^{7}$ We obtained data on the closing prices of all of these contracts from CBOT, going back to February $1991 .^{8}$ The contracts for short horizons are quite liquid, but liquidity drops sharply as the horizon increases. These data include 100 target changes: 86 FOMC meetings and 14 intermeeting rate changes. From 1994 to 2000 inclusive, there were only 2 intermeeting rate changes. We suspect that intermeeting changes are more likely to be associated with the release of macroeconomic information rather than exogenous variation in monetary policy. Therefore we generally work with the FOMC-day changes only.

Measuring the surprise change in the target from the current month contract requires taking account of how far through the month the change occurs. The futures contract refers to the monthly average rate, and a target change later in the month has a smaller effect on the monthly average rate. Thus, we measure the surprise change in the target as

$$
\text { surprise change in target }=\Delta f_{d}^{0}\left(\frac{\text { days in month }}{\text { days left in month }}\right) .{ }^{9}
$$

\footnotetext{
${ }^{7}$ We could potentially gain more horizons by using eurodollar futures contracts. In testing, however, we find that the longer dated futures contracts are not efficient forecasts of the future spot rate, so that an important underlying assumption is not satisfied.

${ }^{8}$ Earlier data exist on some but not all contracts.

${ }^{9}$ If the monthly average rate is $f$ and agents put no mass on a change except on day $d$ out of $T$ days in the month. If the rate starts the month at $x$, the close on day $d-1$ is $f_{d-1}^{0}=d / T x+(T-d) / T z^{e}$ where
} 
Near the end of the month, this adjustment is quite large. Unfortunately, our futures rate data are recorded only to the nearest basis point (to the nearest half basis points since 1995). Thus, our measured changes involve measurement error that is greatly exacerbated when the time-of-month scaling factor is large. For this reason, we take the target surprise to be the change in the next month's contract whenever the change is after the $22^{\text {nd }}$ of the month.

Finally, for a change on the first day of the month there is no prior day for this contract. We measure the surprise change as the difference between the same-month contract price that day and the next-month contract price on the previous day. This approach to decomposing the target rate change into expected and unexpected components using fed funds futures is very similar to that of Kuttner (2001), though it is not the only possible way of measuring the surprise change in the target (see, for example, Söderlind and Svensson (1997)). In the context of United States data, using the fed funds futures seems the most natural approach.

\subsection{Estimating the impulse responses, $r_{h}$}

The futures data are summarized in Table 1. The FOMC-day surprises are small, with over 80 percent falling between -10 and plus 10 basis points. The medians are all zero. The unexpected components of the recent intermeeting changes are much larger.

Under the assumptions outlined above, the relative size of the FOMC-day change at various horizons should be the same but for a scale factor representing the size and sign of

$z$ is the rate expected to prevail for the rest of the month. The close on day $d$ after the announcement is, $f_{d}^{0}=d / T x+(T-d) / T z$, where $z$ is the announced rate. The difference in these is $\Delta f_{d}^{0}=(T-d) / T\left(z-z^{e}\right)$ so the surprise change in the rate for the rest of the month is given by the formula in the text. 
the shock. Thus, the scatter plot of any of these series against any other should be a straight

line. As we see in Figure 1, this linearity assumption appears to be reasonably well satisfied.

The failure of exact linearity obviously implies that our assumptions are not exactly

satisfied. One reason this might be true is that there is rounding error as prices in the fed funds futures market are quoted in whole basis points (half basis points since 1995). Another factor might be the effects of illiquidity of the longer dated contracts. The horizon zero contract is least subject to this problem and, thus, is, we believe the best measured. This explains our choice of using the target surprise as the righthand side variable in the following regressions.

We regressed the FOMC-day change in the contracts for horizons 1 through 5 on the target surprise. We take the impulse responses as the coefficient estimates from these regressions. They are listed in Table 2, along with standard errors. Also reported are the regressions including intermeeting rate changes.

In one month, the effect diminishes to 80 percent of the impact effect, and the effect gradually dissipates to about 60 percent of the initial effect over the next four months. We now turn to using this information to identify a VAR.

\section{Results}

In this section we apply the methodology to a benchmark 6 variable VAR of Christiano, Eichenbaum and Evans (1999). Our dataset consists of monthly observations from January 
1959 through October 2001 on industrial production, CPI, the smoothed change in an index of sensitive commodity prices, the fed funds rate, nonborrowed reserves and total reserves. All of the variables, except the interest rate, are in logs, and the VAR includes 12 lags and a constant. Christiano, Eichenbaum and Evans (CEE) estimate a recursive VAR with the data in that order, calling the shock in the federal funds rate equation the monetary policy shock.

The replication of CEE's work with our data is presented in Figure 2, which includes point estimates from their identification and $95 \%$ bootstrap confidence intervals. Our results correspond very closely to those in CEE. A policy shock that causes a 25 basis point rise in the federal funds rate causes output to fall. The peak effect on output is about $\frac{1}{4}$ of a percentage point and occurs about 18 months after the shock. There is a slight price puzzle in this VAR: prices rise slightly following the contractionary monetary policy shock, before eventually falling. Omitting commodity prices makes this puzzle worse. The impulse response of the federal funds rate to the policy shock in the CEE identification rises for one period and then is sharply reversed. This contrasts with the smooth decline we estimated above, a fact we will investigate further below.

\subsection{Identifying the VAR using the futures market information}

Remember that we can view the identification problem as choosing a vector $\alpha$ and that the 6 elements of $\alpha$ give the impact effect of the policy shock on the 6 variables in the VAR. Although it is not strictly necessary in our method, we bound the parameter space for $\alpha$ 
such that all elements are between -0.25 and 0 , except for the element corresponding to the fed funds rate, which is normalized to 0.25 . The requirement that all other elements of $\alpha$ are nonpositive says that a contractionary policy shock cannot raise output, prices, or the reserves variables contemporaneously. This assumption is commonly applied either formally or informally in the literature (e.g., Faust (1998)). The requirement that these elements of $\alpha$ are greater than -0.25 sets a bound on the absolute magnitude of the contemporaneous effects. We think larger contemporaneous effects than this are highly implausible. Of course, recursive identifications make the stronger restriction that there is no contemporaneous effect on variables such as output and prices that are higher in the ordering.

We test hypotheses about the rank of the matrix $R$ using the method described in Appendix A1. We have data on 6 futures contracts and there are 6 variables in the VAR, so that if the matrix $R$ were of rank 6 then $\alpha$ would be just identified. The hypotheses that $R$ has rank 1 or 2 are clearly rejected (Table 3 ). The hypothesis that it has rank 3 is not rejected. Thus $\alpha$ is not fully identified, and this partial identification means that we will not have any point estimates and must construct confidence intervals in a non-standard way, as described above and explained in detail in Appendix A2.

Since we effectively have only three identifying restrictions, one might suppose that our confidence intervals will be very wide. Under weak identification there will always be certain parameters of the model that are very imprecisely estimated, but as we shall see, even our weak identification is sufficient to shed light on some important questions. 
Figure 3 shows $95 \%$ pointwise confidence intervals on the impulse response of the fed funds rate, output and prices to the monetary policy shock, holding the reduced form parameters fixed at their estimated values. Remember that the range shown in the closest we can come to point estimates in the current context. The confidence intervals are wide, reflecting the weak identification, but still contain some substantive information. In particular, the lower bound of the confidence interval for the impulse response of output to the policy shock is close to the lower bound of the CEE confidence interval for this same impulse response (Figure 2), at horizons of more than about 18 months. In this sense, the output effect of the shock at long horizons cannot be more negative than we found with the recursive identification. Also notice that the confidence interval for the impulse response of prices to the policy shock lies below zero everywhere. In this sense, there is no price puzzle. In contrast, with the recursive identification, there is a small price puzzle in that the point estimate of the impulse response of prices first rises, before falling.

Our estimates of the variance share of output due to the policy shock are much more precise (Table 4). Our confidence intervals for the variance share (again holding the reduced form parameters fixed at their estimated values) go from about 0-15 percent. Our identification is sufficient to conclude that, conditional on the reduced form estimates, only a small proportion of the variance of output is due to exogenous variation in monetary policy.

Figure 4 shows the conservative $90 \%$ confidence intervals for the impulse response of the fed funds rate, output and prices to the monetary policy shock, taking simultaneous 
account of uncertainty in $\alpha$ and the reduced form parameters. The confidence intervals are now substantially wider, but the lower bound of the confidence interval for the impulse response of output to the policy shock is still not far below the lower bound of the CEE confidence interval for this same impulse response, at longer horizons. The upper bound of the confidence interval for the impulse response of prices to the policy shock is around zero. The extra width of the confidence intervals in Figure 4, relative to those in Figure 3, is in part because uncertainty in $\theta$ is being taken into account, but may also be an artefact of their conservative construction based on the Bonferroni inequality.

Our confidence intervals for the variance share of output due to the policy shock taking simultaneous account of uncertainty in $\alpha$ and the reduced form parameters (Table 4 ) are not much wider than the CEE confidence intervals and cover essentially the same range: about zero to one-third. We bring additional information to bear (the futures data) while using much weaker identifying assumptions, but the resulting inference about the variance share of output due to the policy shock is about the same.

While our variance share result is consistent with CEE and much other work in the identified VAR literature, Faust (1998) finds that allowing a small contemporaneous response of output instead of imposing a zero effect allowed for variance shares around $2 / 3$. Since we have no strong justification for imposing an effect that is precisely zero, the conclusion of small variance shares in the literature was not on a firm foundation. Our approach imposes restrictions very similar to Faust's and does allow contemporaneous responses of all variables. 
By adding that the funds rate response must match the futures market, however, we rule out the identifications with large variance shares. Faust finds that if the funds rate response to the shock is required to remain positive for 9 months, large variance shares are ruled out. The funds rate futures data seems provides a rational for imposing persistence in this effect.

\subsection{Testing the validity of the recursive identification}

Our method drops many strong restrictions implied by the recursive identification. The benefit is that we do not have to be concerned about robustness of our results to minor changes and plausible changes in assumptions such as allowing small changes where recursion imposes zeros. The cost is that confidence intervals for some items are quite wide. Thus, it is worth checking whether the recursive identification can be maintained in the face of the information from the futures market.

The $\alpha$ implied by the CEE identification is simply the fourth column of the Cholesky factor of the covariance matrix of the reduced form errors, using the CEE ordering of the variables (in which the fed funds rate comes fourth). This choice of $\alpha$ is not included in the confidence set $A$. In other words, the recursive identification is rejected by the futuresmarket-based identification.

The recursive identification makes the assumptions that the monetary policy shock has no contemporaneous effect on either output or prices, amongst other things. We constructed the confidence set $A$ by our identification but imposing the restriction that the coefficient in $\alpha$ corresponding to prices and output are both zero. The confidence set so constructed was 
empty. That is, there does not exist any identification with a zero contemporaneous effect on output that is consistent with our identification.

\section{Support for the identifying assumptions}

Our approach to identification relies on the following three principle assumptions.

1. The VAR is an adequate representation of the reduced form.

2. The futures market provides an efficient forecast of the change in the trajectory of the funds rate, or at least risk premia in the fed funds futures markets do not change on the day of our policy announcements.

3. The change in the futures rates on our policy announcement days is due to the policy shock we wish to analyze. No other news moves the market and the policy announcement itself does not reveal information about other shocks.

We take up these assumptions in order in this section.

\subsection{Is the VAR is an adequate representation of the reduced form?}

This assumption is common to the entire identified VAR literature. We will use conventional VARs and our results rest on this assumption just as the earlier work does.

Rudebusch (1998) pointed out that the funds rate forecasts implied by the futures market have little correlation with the forecasts generated from a reduced form VAR. Robertson and Tallman (2001) argue that the correlation between the two sets of forecasts can be greatly 
increased if the VAR is estimated with Bayesian shrinkage methods, instead of the usual least squares estimation. Shrinkage methods often enhance the forecasting performance of highly parameterized VARs. Motivated by this, we redid the analysis reported above, but replacing OLS estimates of the VAR with the posterior mean, constructed as described by Robertson and Tallman. Our substantive conclusions are not affected by this modification.

\subsection{Are Federal Funds Futures Rates Efficient Forecasts?}

We test the efficiency of the interest rate futures market by regressing the average effective federal funds rate for month $t$ on the forecast for month $t$ implicit in the fed funds futures market in the middle ${ }^{10}$ of months $t-1, t-2, t-3, t-4$ and $t-5$. The regressions therefore constitute standard forecast efficiency regressions for evaluating $h$-step ahead forecasts of interest rates from the fed funds futures market. Under the null hypothesis of forecast rationality, the intercept should be zero and the slope coefficient should be one. The results (Table 5) support the idea that the fed funds futures market provides efficient forecasts of the trajectory of future interest rates. The null hypothesis that the slope/intercept are jointly equal to zero/one is accepted for all horizons. For all horizons the intercept is not significantly different from zero and the slope is not significantly different from one. Actually, a non-zero intercept is not a problem for our methods in itself, as this could just represent a constant risk premium; only time-varying risk premia that might vary in response to a monetary policy shock undermine our identification. Similar support for the efficiency of the fed funds

\footnotetext{
${ }^{10}$ More precisely, this is the closing price on the 15 th day, or next business day, of month $\mathrm{t}-1$.
} 
futures market was reported by Krueger and Kuttner (1996) and Rudebusch (1998), though they used shorter samples.

\subsection{Is the target change purely due to the policy shock?}

There are two ways that this assumption could fail. The simplest way is that other important information could hit the market on the day of announced target changes. Second, the Fed's announcement could reveal private information of the Fed about the state of the economy.

We checked whether any of important pieces of macro data were announced on the day of FOMC meetings. We find that on the FOMC days in our sample retail sales were released once, durable goods, GDP and PPI were released twice each, industrial production was released three times and CPI was released 6 times. The clear majority of FOMC days are not also days of important macroeconomic data releases. The Federal Reserve might, however, have an information advantage through earlier access to data (especially data that are produced by the Federal Reserve, such as industrial production) or through superior economic analysis provided by the Fed's staff economists.

We conducted a test, the intuition for which is as follows. We form a measure of the surprise component of macroeconomic data announcements based on survey measures of expectations. We collect those instances where the survey is taken just before an FOMC meeting and the data come out just afterward. If the fed funds target surprise effectively releases macro data, then the target surprise should be correlated with the macro announcement surprise. In this case, the target surprise can be used by the market to update its 
expectation of the macro announcement.

The details of our test are as follows. For each FOMC meeting the test involves regressing the next monthly release of a macroeconomic indicator on (i) the target rate surprise on the day of the FOMC meeting and (ii) the forecast for that macroeconomic release made by Wrightson Associates on the Friday before the FOMC meeting. We test the hypothesis that the coefficient on the target rate surprise is equal to zero. We consider the following macroeconomic indicators: nonfarm payrolls, CPI, industrial production, retail sales, real GDP and the GDP deflator. ${ }^{11}$ In the regression corresponding to each macroeconomic indicator, we omit any FOMC meeting that occurs after the date of the release of that macroeconomic indicator for that month. Because each macroeconomic release refers to the previous month, the target rate surprise can have predictive power for the macroeconomic release only through the Federal Reserve having an information advantage, and not through any contemporaneous effects of the target rate surprise.

Applying this test, we find that the estimated coefficient on the target surprise is not significantly different from zero for any macroeconomic indicator (Table 6), except for industrial production which is significant at the $5 \%$ level, though not at the $1 \%$ level. Of course, the industrial production data are produced by the Fed and it is plausible that the Fed has an informational advantage in this regard. Overall, however, we believe that our

\footnotetext{
${ }^{11}$ Note that there is a GDP release every month, although this data is quarterly. The first month of every quarter, there is the first release of GDP for the previous quarter while a revision, referring to this same quarter, is then released in each of the next two months.
} 
assumption that the FOMC decision is primarily a policy shock is supported.

\subsection{Alternative term structures}

Since our estimates of the impulse response of the funds rate from the futures market are subject to criticism, we also explored the sensitivity of our primary conclusion to the specifics of the imposed term structure.

In particular, we imposed that the impulse response of the funds rate to the policy shock starts at +25 basis points and then over the next 5 months grows or diminishes linearly to $1.5,1.25,1,0.75,0.5,0.25,0$, and -0.25 and -0.5 times its impact effect. The resulting confidence intervals for the variance shares of output due to the policy shock are reported in Table 7 (these take simultaneous account of the uncertainty in $\alpha$ and $\theta$ ). Large variance shares are only included in the confidence interval if the monetary policy shock goes to zero or reverses sign within 5 months. This is manifestly at odds with the evidence from the futures market.

A recent paper by Ellingsen and Söderström (2001) discusses the changes in the federal funds target between 1988 and 1997 and classifies some market responses as due to exogenous policy shifts, and others as an endogenous response to asymmetric information. The classification is based on their reading of the Wall Street Journal. Although one might be somewhat skeptical of this classification, we estimated the impulse responses $r_{h}$ by regressing the FOMC-day change in the contracts for horizons 1 through 5 on the target surprise using only changes that Ellingsen and Söderström classify as exogenous policy shifts. Our 
confidence intervals for the variance shares of output due to the policy shock using these estimated impulse responses as the basis of our identification are not very different from those obtained in the baseline case (Table 4).

\subsection{Caveats}

Ultimately, all work identifying the effects of policy shocks is subject to many potential criticisms. Our goal is not to find the mythical fully credible identification. We have attempted to be clear about the principle assumptions our identification rests on and to support these assumptions. We argue that our approach is plausible, even more plausible than standard recursive approaches.

We are hopeful about two strategies for progress that are illustrated in this paper. First, we believe it important to generate different approaches to identification. If very different approaches give similar answers, those answers become more plausible. Second, we believe it is important to bring more information to bear than the much-studied, standard 6 or 10 macro variables. This paper provides one approach to doing this and finds renewed support, for example, for the conclusion that policy shocks account for a small part of the variance share of output.

\section{Conclusions}

Fed funds futures have been used by a number of authors to analyze various aspects of 
monetary policy. Our motivation in this paper has been to use these data to aid in the structural identification of a standard monetary policy VAR.

The basic idea in this paper is to assume that the surprise component of the Fed's decision on FOMC day (measured from the futures market) represents exogenous variation in monetary policy. We use this high frequency data to form identifying restrictions for a monthly VAR. Specifically, we impose that the response of the fed funds rate to policy shocks must match that estimated in the futures market. The method can also apply to the response of any data in the VAR that is observed at high frequency around a monetary policy shock (measured in this or any other way). For example, it would be possible to measure the effect of the monetary policy shock on the exchange rate and to use this information to assist in the identification of a low frequency structural VAR.

In the specific model that we have considered in this paper, we reach four conclusions. First, we reject the standard recursive identification. It appears that the standard assumption that the contemporaneous output and price responses to the policy shock are zero is one factor at the root of this rejection. Secondly, we find that the negative effect of a monetary policy tightening on output at longer lags cannot be much larger than was found with the standard recursive identification. Thirdly, we find that the effect of a monetary policy tightening is to reduce the price level at all horizons that we consider. Finally, we find evidence in support of the conclusion that only a small fraction of the variance of output can be attributed to monetary policy shocks. We have done so using an alternative 
identifying assumption that is quite different, and, we would argue, more plausible, than the conventional short-run restrictions.

\section{Appendix}

\section{A1 Testing the rank of $R$}

We wish to test the hypothesis that $\rho(R)=L$ against the alternative that $\rho(R)>L$, where $\rho($.$) denotes the rank of the argument. Assume that T^{1 / 2}(\hat{\theta}-\theta) \rightarrow_{d} N\left(0, V_{\theta}\right)$. See Hamilton (1994) for primitive conditions for this convergence results and $\hat{V}_{\theta}$, a consistent estimator of $V_{\theta}$. The matrix $R$ is a nonlinear function of $\theta$ and can be estimated by $\hat{R}$, where this denotes this same nonlinear function of $\hat{\theta}$. By the delta method, $T^{1 / 2}(\operatorname{vec}(\hat{R})-\operatorname{vec}(R)) \rightarrow_{d}$ $N\left(0, V_{R}\right)$ where $V_{R}=\frac{\operatorname{dvec}(R)^{\prime}}{d \theta} V_{\theta} \frac{d v e c(R)}{d \theta}$.

To test the hypothesis about that rank of $R$, we use the test statistic

$$
T \min _{P \varepsilon \pi(L)}(\operatorname{vec}(\hat{R})-\operatorname{vec}(P))^{\prime} \hat{V}_{R}^{-1}(\operatorname{vec}(\hat{R})-\operatorname{vec}(P))
$$

where $\hat{V}_{R}$ is $\frac{d v e c(\hat{R})^{\prime}}{d \theta} \hat{V}_{\theta} \frac{\operatorname{dvec}(\hat{R})}{d \theta}$ and $\pi(L)$ is the space of all conformable matrices of rank $L$. By Theorem 1 of Cragg and Donald (1997), under the null hypothesis, this test statistic has a $\chi^{2}$ null limiting distribution.

\section{A2 Partial Identification}

Here we describe how to construct the confidence set $A$ for the vector $\alpha$ when the restrictions $R \alpha=r$ must be satisfied, $R$ is estimated by $\hat{R}, r$ is estimated by $\hat{r}, R$ may be rank deficient, 
$T^{1 / 2}(\operatorname{vec}(\hat{R})-\operatorname{vec}(R)) \rightarrow_{d} N\left(0, V_{R}\right)$ and $T^{1 / 2}(\hat{r}-r) \rightarrow_{d} N\left(0, V_{r}\right)$. Consider the GMM objective function

$$
S(\alpha)=T(\hat{R} \alpha-r)^{\prime}\left[\left(\alpha \otimes I_{K}\right) \hat{V}_{R}\left(\alpha^{\prime} \otimes I_{K}\right)+\hat{V}_{r}\right]^{-1}(\hat{R} \alpha-r) .
$$

In standard GMM terminology, this is the continuous updating GMM objective function. The estimator $\hat{\alpha}$ that minimizes this objective function is not consistent for the true $\alpha$ because of the rank deficiency of the matrix $R$. However $S\left(\alpha_{0}\right)$ has a $\chi^{2}$ null distribution regardless of the rank of $R$ where $\alpha_{0}$ denotes the true value of the vector $\alpha$. Accordingly, the confidence set

$$
A=\left\{\alpha \varepsilon A^{+}: S(\alpha) \leq F_{\chi^{2}}\right\}
$$

is a confidence set for $\alpha$ with asymptotic coverage $95 \%$, regardless of the rank of $R$, where $F_{\chi^{2}}$ denotes the 95 th percentile of a $\chi^{2}$ distribution (degrees of freedom equal to the number of elements in $r$ ). This confidence set is therefore immune to the rank deficiency of $R$.

The use of such confidence sets in models that are not fully identified was proposed by Stock and Wright (2000), where they are referred to as S-sets. If the matrix $R$ is rank deficient, then there exists a subspace of vectors $\alpha$ that are observationally equivalent to $\alpha_{0}$. Any vector in this subspace must be included in $A$ with probability $95 \%$, asymptotically. Any other vector $\alpha$ will be excluded from $A$ with probability 1, asymptotically. This is a correct statement of what we do and do not know about $\alpha$, when $R$ is rank deficient. More formally, the confidence set $A$ is unbounded with probability 0.95 , asymptotically: 
this must be the case for any confidence set for an unidentified parameter if the confidence set is to have $95 \%$ asymptotic coverage uniformly in the parameter space (Dufour (1997)). Notwithstanding the fact that our confidence set for $\alpha$ is unbounded, the confidence interval for a nonlinear function of $\alpha$ and $\theta$, such as a variance share, does not necessarily have to be unbounded.

\section{References}

Christiano, L.J., M. Eichenbaum and C.L. Evans (1996): The Effects of Monetary Policy Shocks: Evidence from the Flow of Funds, Review of Economics and Statistics, 78, pp.16-34. Christiano, L.J., M. Eichenbaum and C.L. Evans (1999): Monetary Policy Shocks: What Have we Learned and to What End? in Handbook of Macroeconomics, Volume 1A, J. Taylor and M. Woodford (eds.).

Cochrane, J.H. and M. Piazzesi (2002): The Fed and Interest Rates: A High Frequency Identification, American Economic Review Papers and Proceedings, forthcoming.

Cragg, J.G. and S.G. Donald (1997): Inferring the Rank of a Matrix, Journal of Econometrics, 76, pp.223-250.

Dufour, J.M. (1997): Some Impossibility Theorems in Econometrics with Applications to Structural and Dynamic Models, Econometrica, 65, pp.1365-1387.

Ellingsen, T. and U. Söderström (2001): Monetary Policy and Market Interest Rates, American Economic Review, 91, pp.1594-1607. 
Faust, J. (1998): The Robustness of Identified VAR Conclusions about Money, CarnegieRochester Series on Public Policy, 49, pp.207-244.

Hamilton, J.D. (1994): Time Series Analysis, Princeton University Press, Princeton.

King, R.G. and M.W. Watson (1997): Testing Long Run Neutrality, Federal Reserve Bank of Richmond Economic Quarterly, 83, pp.69-101.

Leeper, E.M., C.A. Sims and T. Zha (1996): What Does Monetary Policy Do?, Brooking Papers on Economic Activity, 2, pp.1-63.

Krueger, J.T. and K.N. Kuttner (1996): The Fed Funds Futures Rate as a Predictor of Federal Reserve Policy, Journal of Futures Markets, 16, pp.865-879.

Kuttner, K.N. (2001): Monetary Policy Surprises and Interest Rates: Evidence from the Fed Funds Futures Market, Journal of Monetary Economics, 47, pp. 523-44.

Robertson, J.C. and E.W. Tallman (2001): Improving Federal Funds Rate Forecasts in VAR Models Used for Policy Analysis, Journal of Business and Economic Statistics, 19, pp.324-330.

Rudebusch, G. (1998): Do Measures of Monetary Policy in a VAR Make Sense?, International Economic Review, 39, pp.907-932.

Sims, C.A. (1980): Macroeconomics and Reality, Econometrica, 48, pp.1-48.

Söderlind, P. and L.E.O. Svensson (1997): New Techniques to Extract Market Expectations from Financial Instruments, Journal of Monetary Economics, 40, pp.383-429.

Stock, J.H. and J.H. Wright (2000): GMM with Weak Identification, Econometrica, 68, 
pp.1055-1096.

Uhlig, H. (1997): What are the Effects of Monetary Policy on Output? Results from an Agnostic Identification Procedure, Center for Economic Policy Research Discussion Paper, London. 
Table 1: Summary of futures rate changes on FOMC days and days of intrameeting

\begin{tabular}{ccccccc}
\multicolumn{7}{c}{ changes } \\
\hline \hline \multicolumn{7}{c}{ FOMC day percentiles } \\
& target & $\mathrm{t}+1$ & $\mathrm{t}+2$ & $\mathrm{t}+3$ & $\mathrm{t}+4$ & $\mathrm{t}+5$ \\
$10 \mathrm{th}$ & -7.00 & -8.00 & -7.00 & -8.00 & -10.00 & -9.00 \\
$25 \mathrm{th}$ & -3.58 & -2.00 & -2.00 & -2.50 & -3.00 & -3.00 \\
$50 \mathrm{th}$ & 0.00 & 0.00 & 0.00 & 0.00 & 0.00 & 0.00 \\
75 th & 1.11 & 1.00 & 1.00 & 2.00 & 2.00 & 2.00 \\
$90 \mathrm{th}$ & 6.00 & 4.00 & 4.00 & 4.00 & 4.00 & 5.00
\end{tabular}

Intrameeting changes, actual values

\begin{tabular}{lllllll}
$4 / 18 / 1994$ & 10 & 10 & 10 & 12 & 14 & 16 \\
$10 / 15 / 1998$ & 3.88 & 6 & 7 & 8 & 4 & 5 \\
$1 / 3 / 2001$ & -38.2 & -29 & -26 & -21.5 & -20 & -14 \\
$4 / 18 / 2001$ & -42.5 & -42 & -35 & -31.5 & -33.5 & -29 \\
\hline \hline
\end{tabular}

Notes: Rates are reported in basis points. The top panel reports percentiles of the distribution, the bottom panel reports the actual data for the four changes on the dates indicated. The "target" column is the surprise changes in the target as discussed in the text.

Table 2: Measures of the impulse response of the funds rate to a policy shock

\begin{tabular}{lllll}
\hline \hline & FOMC Only & \multicolumn{2}{c}{ With Intermeeting Changes } \\
horizon & rel. response & Std. err. & rel. response & Std. err. \\
$t+1$ & 0.81 & 0.04 & 0.81 & 0.03 \\
$t+2$ & 0.67 & 0.07 & 0.73 & 0.04 \\
$t+3$ & 0.62 & 0.07 & 0.69 & 0.05 \\
$t+4$ & 0.63 & 0.09 & 0.73 & 0.05 \\
$t+5$ & 0.57 & 0.09 & 0.67 & 0.06 \\
\hline \hline
\end{tabular}

Notes: Regression is the result of a least squares regression of the change in the futures rate on the target surprise with no intercept. 
Table 3: Test of the rank of $R$ in $R \alpha=r$

$$
\begin{array}{cc}
\multicolumn{2}{c}{(\mathrm{p} \text {-values })} \\
\hline \hline p=0 & 996.67 \\
& (0.00) \\
p=1 & 47.76 \\
& (0.00) \\
p=2 & 6.80 \\
& (0.87) \\
p=3 & 1.22 \\
& (0.98) \\
p=4 & 0.30 \\
& (0.86) \\
\hline \hline
\end{array}
$$


Table 4: Output forecast error variance shares under alternate identifications

\begin{tabular}{|c|c|c|c|c|c|c|c|c|c|c|}
\hline & \multicolumn{2}{|c|}{$\overline{v_{12}}$} & \multicolumn{2}{|c|}{$v_{24}$} & \multicolumn{2}{|c|}{$v_{36}$} & \multicolumn{2}{|c|}{$v_{48}$} & \multicolumn{2}{|c|}{$v_{60}$} \\
\hline & lower & upper & lower & upper & lower & upper & lower & upper & lower & upper \\
\hline & \multicolumn{10}{|c|}{ CEE identification } \\
\hline CEE pt. & \multicolumn{2}{|c|}{0.08} & \multicolumn{2}{|c|}{0.13} & \multicolumn{2}{|c|}{0.12} & \multicolumn{2}{|c|}{0.11} & \multicolumn{2}{|c|}{0.10} \\
\hline CEE & 0.01 & 0.21 & 0.02 & 0.33 & 0.02 & 0.32 & 0.02 & 0.31 & 0.02 & 0.30 \\
\hline & \multicolumn{10}{|c|}{ futures-data identification } \\
\hline Fixed $\hat{\theta}$ & 0.00 & 0.20 & 0.00 & 0.15 & 0.00 & 0.10 & 0.00 & 0.13 & 0.00 & 0.14 \\
\hline Uncertain $\alpha$ and $\theta$ & 0.00 & 0.35 & 0.00 & 0.31 & 0.00 & 0.23 & 0.00 & 0.34 & 0.00 & 0.37 \\
\hline
\end{tabular}


Table 5: Forecast efficiency tests for interest rate futures

\begin{tabular}{llll}
\hline \hline & $\begin{array}{l}\hat{\alpha} \\
\text { (t-stat })\end{array}$ & $\begin{array}{l}\hat{\beta} \\
\text { (t-stat })\end{array}$ & $\begin{array}{l}p-\text { val } \\
(\alpha=0, \beta=1)\end{array}$ \\
\hline 1 month ahead & $\begin{array}{l}-0.05 \\
(-0.41)\end{array}$ & $\begin{array}{l}1.00 \\
(0.13)\end{array}$ & 0.42 \\
& & & \\
2 months ahead & -0.06 & 1.00 & 0.30 \\
& $(-0.31)$ & $(-0.02)$ & \\
& & & \\
3 months ahead & -0.03 & 0.99 & 0.26 \\
& $(-0.09)$ & $(-0.25)$ & \\
4 months ahead & 0.10 & 0.95 & 0.26 \\
& $(0.22)$ & $(-0.55)$ & \\
5 months ahead & $\begin{array}{l}\text { 0.30 } \\
(0.49)\end{array}$ & $\begin{array}{l}0.90 \\
(-0.82)\end{array}$ & 0.22 \\
\hline \hline
\end{tabular}

Notes: The regression is $f_{t+h}=\alpha+\beta f_{t}^{h}+$ error 
Table 6: Tests of the exogeneity of the monetary policy shocks

\begin{tabular}{|c|c|c|c|}
\hline $\begin{array}{l}\text { Macroeconomic } \\
\text { Indicator }\end{array}$ & Intercept & $\begin{array}{l}\text { Coefficient on } \\
\text { Forecast } \\
\end{array}$ & $\begin{array}{l}\text { Coefficient on } \\
\text { FOMC Surprise }\end{array}$ \\
\hline $\begin{array}{l}\text { Nonfarm Payrolls } \\
\text { (mom change, 000s) }\end{array}$ & $\begin{array}{l}-31.54 \\
(34.03)\end{array}$ & $\begin{array}{l}1.17 \\
(0.19)\end{array}$ & $\begin{array}{l}335.07 \\
(272.89)\end{array}$ \\
\hline $\begin{array}{l}\text { CPI } \\
\text { (mom change, percent) }\end{array}$ & $\begin{array}{l}0.00 \\
(0.05)\end{array}$ & $\begin{array}{l}0.75 \\
(0.17)\end{array}$ & $\begin{array}{l}-0.25 \\
(0.31)\end{array}$ \\
\hline $\begin{array}{l}\text { Industrial Production } \\
\text { (mom change, percent) }\end{array}$ & $\begin{array}{l}0.04 \\
(0.07)\end{array}$ & $\begin{array}{l}0.72 \\
(0.19)\end{array}$ & $\begin{array}{l}2.03 \\
(0.86)\end{array}$ \\
\hline $\begin{array}{l}\text { Retail Sales } \\
\text { (mom change, percent) }\end{array}$ & $\begin{array}{l}-0.08 \\
(0.13)\end{array}$ & $\begin{array}{l}1.54 \\
(0.15)\end{array}$ & $\begin{array}{l}0.34 \\
(1.68)\end{array}$ \\
\hline $\begin{array}{l}\text { Real GDP } \\
\text { (qoq change, ann percent) }\end{array}$ & $\begin{array}{l}0.05 \\
(0.12)\end{array}$ & $\begin{array}{l}1.00 \\
(0.03)\end{array}$ & $\begin{array}{l}-0.39 \\
(1.21)\end{array}$ \\
\hline $\begin{array}{l}\text { GDP Deflator } \\
\text { (qoq change, ann percent) }\end{array}$ & $\begin{array}{l}0.08 \\
(0.09)\end{array}$ & $\begin{array}{l}0.94 \\
(0.04)\end{array}$ & $\begin{array}{l}-0.59 \\
(0.66)\end{array}$ \\
\hline
\end{tabular}


Table 7: Robustness check: output forecast error variance shares assuming that the impulse response of the monetary policy shock on the Fed Funds rate goes from 25 basis points to $25 \lambda$ basis points, linearly, going from the month of the shock to 5 months later.

\begin{tabular}{lcccccccccc}
\hline \hline$\lambda$ & \multicolumn{3}{c}{$v_{12}$} & \multicolumn{2}{c}{$v_{24}$} & \multicolumn{2}{c}{$v_{36}$} & \multicolumn{2}{c}{$v_{48}$} & \multicolumn{2}{c}{$v_{60}$} \\
& lower & upper & lower & upper & lower & upper & lower & upper & lower & upper \\
\hline & & & & & & & & & & \\
1.5 & 0.00 & 0.05 & 0.00 & 0.20 & 0.00 & 0.12 & 0.00 & 0.22 & 0.00 & 0.24 \\
1.25 & 0.00 & 0.21 & 0.00 & 0.14 & 0.00 & 0.24 & 0.00 & 0.25 & 0.00 & 0.26 \\
1 & 0.00 & 0.27 & 0.00 & 0.12 & 0.00 & 0.28 & 0.00 & 0.23 & 0.00 & 0.29 \\
0.75 & 0.00 & 0.33 & 0.00 & 0.34 & 0.00 & 0.31 & 0.00 & 0.26 & 0.00 & 0.29 \\
0.5 & 0.00 & 0.40 & 0.00 & 0.38 & 0.00 & 0.32 & 0.00 & 0.34 & 0.00 & 0.37 \\
0.25 & 0.00 & 0.48 & 0.00 & 0.42 & 0.00 & 0.33 & 0.00 & 0.35 & 0.00 & 0.38 \\
0 & 0.00 & 0.54 & 0.00 & 0.46 & 0.00 & 0.36 & 0.00 & 0.36 & 0.00 & 0.39 \\
-0.25 & 0.00 & 0.59 & 0.00 & 0.49 & 0.00 & 0.37 & 0.00 & 0.35 & 0.00 & 0.39 \\
-0.5 & 0.00 & 0.60 & 0.00 & 0.51 & 0.00 & 0.40 & 0.00 & 0.34 & 0.00 & 0.39 \\
\hline \hline
\end{tabular}

Notes: These confidence intervals allow for simultaneous uncertainty in $\alpha$ and $\theta$ 
Fig. 1: Target surprise and futures rate changes (basis points)

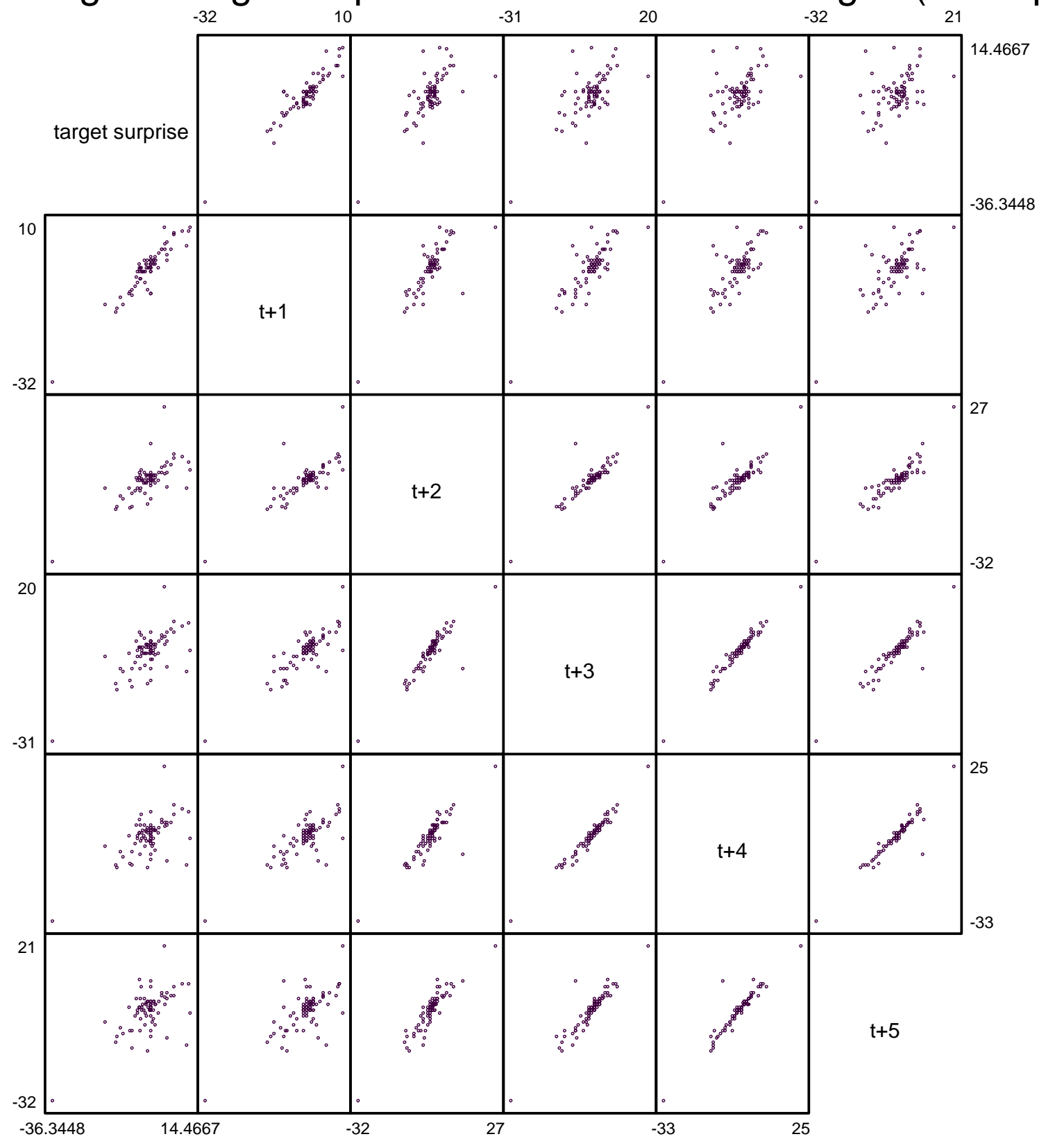


Fig.2: Estimated Impulse Responses and Bootstrap Intervals in CEE Identification
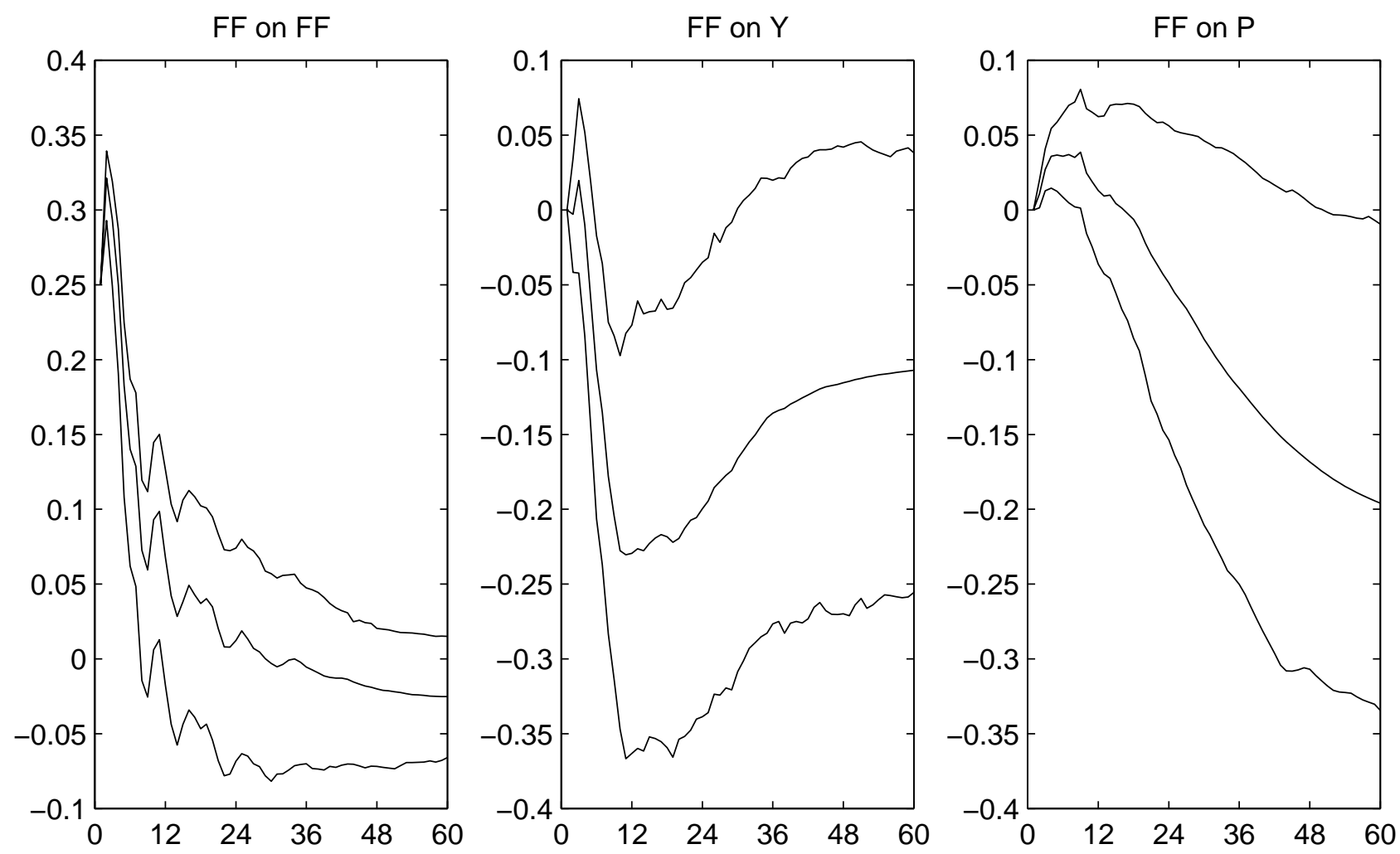

FF on PCOM
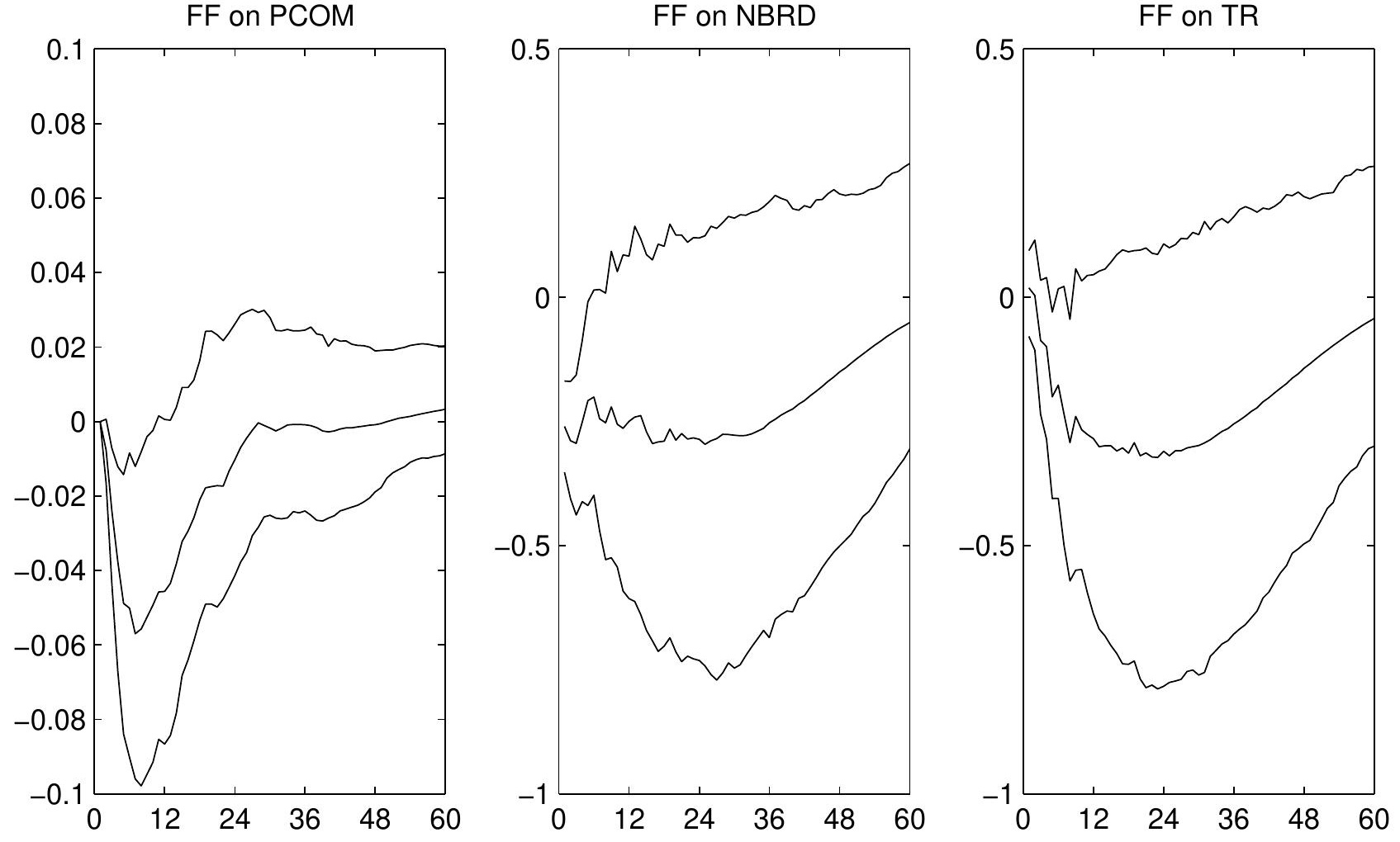
